\title{
Comparative proteomics reveals proteins impacted by nitrogen deprivation in wild-type and high lipid-accumulating mutant strains of Tisochrysis lutea
}

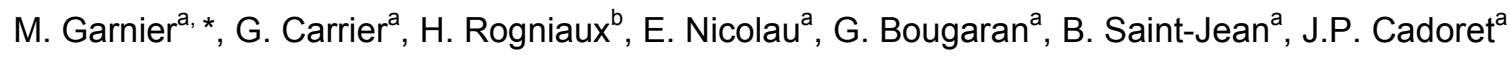 \\ 1 Laboratoire BRM-PBA Ifremer, Nantes, France \\ 2 INRA, UR1268 Biopolymers Interactions Assemblies F-44316 NANTES, France \\ *: Corresponding author: Matthieu Garnier, tel.: + 33240374336 ; fax: + 33240374001 ; \\ email address : mgarnier@ifremer.fr
}

\begin{abstract}
:
Understanding microalgal lipid accumulation under nitrogen starvation is of major interest for biomass feedstock, food and biofuel production. Using a domesticated oleaginous algae Tisochrysis lutea, we performed the first comparative proteomic analysis on the wild type strain and a selected lipid overaccumulating mutant. 2-DE analysis was made on these strains cultured in two metabolic conditions, with and without nitrogen deprivation, which revealed significant differences in proteomes according to both strain and nitrogen availability. Mass spectrometry allowed us to identify 37 proteins that were differentially expressed between the two strains, and 17 proteins regulated by nitrogen starvation concomitantly with lipid accumulation. The proteins identified are known to be involved in various metabolic pathways including lipid, carbohydrate, amino acid, energy and pigment metabolisms, photosynthesis, protein translation, stress response and cell division. Four candidates were selected for possible implication in the over-accumulation of lipids during nitrogen starvation. These include the plastid beta-ketoacyl-ACP reductase protein, the coccolith scale associated protein and two glycoside hydrolases involved in biosynthesis of fatty acids, carbon homeostasis and carbohydrate catabolism, respectively. This proteomic study confirms the impact of nitrogen starvation on overall metabolism and provides new perspectives to study the lipid over-accumulation in the prymnesiophyte haptophyte T. lutea.
\end{abstract}

\section{Biological significance}

This paper study consists of the first proteomic analysis on Tisochrysis lutea, a non-model marine microalga of interest for aquaculture and lipids production. Comparative proteomics revealed proteins putatively involved in the up-accumulation of neutral lipids in a mutant strain during nitrogen starvation. The results are of great importance for future works to improve lipid accumulation in microalgae of biotechnological interest for biofuel production. This article is part of a Special Issue entitled:

Proteomics of non-model organisms. 


\section{Graphical abstract}

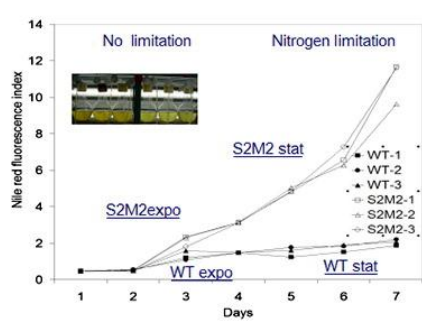

Neutral lipid accumulation in batch

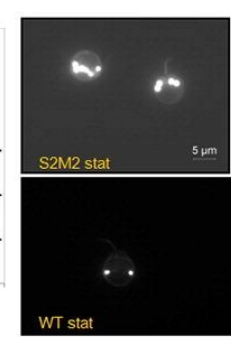

Lipid droplets

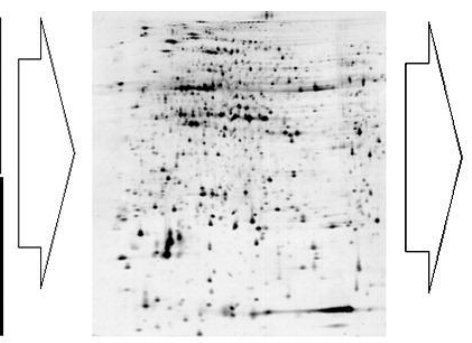

x24 2-DE gels

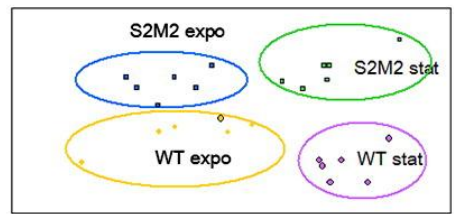

PCA on normalized spot volume (1850 spots $\times 24$ gels)
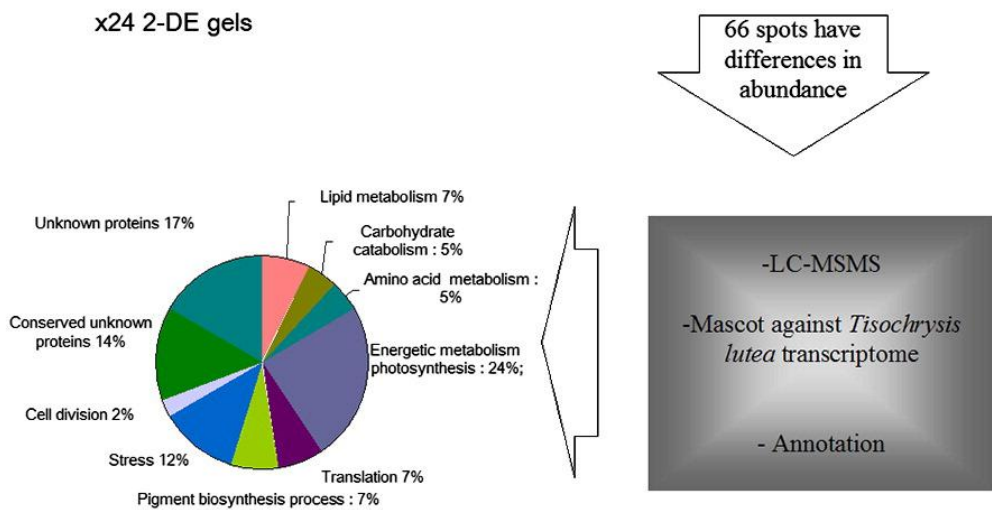

MS-MS and functionnal annotation

Selection of proteins putatively involved in up accumulation of neutral lipids in S2M2 during $N$ limitation.

\section{Highlights}

We studied growth and lipid build-up in Tisochrysis lutea WT and a selected mutant. Lipid droplets of the mutant were larger and more numerous during nitrogen limitation. 2-DE and MS revealed 17 proteins affected by nitrogen limitation. 2-DE and MS revealed 37 proteins affected by strain selection. We propose a set of proteins potentially involved in lipid over-accumulation.

Keywords : Microalgae ; Biotechnology ; Lipid ; Nitrogen ; Proteomic ; Selection ; Biotechnology 


\section{Introduction}

The metabolism of lipids in microalgae has attracted new interest over the last few years because of the energetic potential offered by these photosynthetic microorganisms [1]. Algal lipids are also of interest for human health as they include the long chain polyunsaturated fatty acids (PUFAs) arachidonic, eicosapentaenoic and docosahexaenoic acid, which are transferred via the food chain and protect humans against cardiovascular diseases [2] [3] [4]. Moreover, some species can produce high amounts of neutral lipids such as triacylglycerols (TAGs) that can be used to produce $3^{\text {rd }}$ generation biofuel [5], although cost effectiveness of such methods remains in question [6], [7].

Enhancement of TAGs in most microalgae is known to be triggered by stress and nutrient deprivation, particularly nitrogen deprivation [2,8]. TAGs accumulate in lipid droplets and play roles in carbon and energy storage, as a source of long chain PUFAs, and in photooxidation prevention [8]. Because the increase of lipid production is of great biotechnological interest, one of the current important research objectives is to understand the molecular mechanisms that govern lipid accumulation under nitrogen starvation.

Chlamydomonas reinhardtii is the most commonly used algae model. The availability of starchless mutants that over-accumulate neutral lipids have facilitated investigations on lipid metabolism $[1,4,9-$ 13]. Although de novo FA biosynthesis and TAG build-up have been quite well described, the regulation of lipid biosynthesis remains poorly understood in this model species. In oleaginous algae, many fundamental biological questions relating to the biosynthesis and regulation of lipids need to be answered in order to allow more efficient lipid management. Post genomics has been shown to be a good way to develop biotechnology of microalgae including non-model species (for review see [14]). Thereby, transcriptomics has been used to study the effects of nitrogen starvation in the chlorophyceae Micractinium pisillum, the eustigmatophyceae Nannochloropsis sp. and the diatom Phaeodactylum tricornutum [15-18]. The results suggest that the carbon sources for neutral lipid accumulation could be largely derived from carbohydrates and that the acetyl-CoA metabolism would play an important role in driving carbon flow into TAG biosynthesis. In Nannochloropis gaditana transcripts of a few genes involved in lipid biosynthesis were increased significantly during rapid nitrogen deprivation [19]. Proteomics allows us to study the changes of the final products of gene 
regulation, namely the proteins, from transcription until post-translational modifications. This approach, in complement to transcriptomic analysis, was implemented to examine the responses of Nannochloropsis oceanica to long-term nitrogen starvation [20]. Proteomics analysis of the chlorophyceae Chlorella vulgaris in response to nitrogen starvation revealed the up regulation of proteins involved in de novo fatty acid biosynthesis and in the build-up of TAGs [21]. Moreover, the authors suggested that post-transcriptional regulation of key enzymes was important in the regulation of fatty acid synthesis. This highlights the interest of proteomic approaches for understanding lipid metabolism in neutral lipid-rich microalgae.

Tisochrysis lutea (T. lutea), previously named Isochrysis aff. galbana (Clone Tahiti) [22] is a small uncalcified prymnesiophyte haptophyte. Numerous ecophysiological studies have focused on haptophytes because of their extensive use as feeds in aquaculture. Isochrysidales naturally contain large amount of fatty acids and PUFAs and under nitrogen starvation they accumulate high amounts of polyunsaturated long-chain (C37-39) alkenes and alkenones (PULCA) rather than TAGs [23-27]. Recently, our laboratory implemented one of the first domestication strategies based on successive rounds of UV mutation and cell sorting. This non-GMO (Genetic Modified Organism) selection approach allowed us to obtain a Tisochrysis lutea strain (T. Iutea-S2M2) that accumulates twice the amount of neutral lipids under nitrogen starvation, with no decrease in growth rate compared to the wild type strain (WT) [28]. In order to maximize the yield of lipid products from microalgae, it is vital to improve our understanding of the mechanisms involved in the over-accumulation of lipids in selected mutants. Because home made transcriptome is available for Tisochrysis lutea and because a high lipid-accumulating mutant (S2M2) was selected, we proposed to use the T. lutea WT and S2M2 strains as models to study lipid metabolism in haptophytes in relation to nitrogen starvation.

Therefore, in this work, we applied a comparative proteomics study to learn more about the molecular mechanisms affected, firstly by selection and secondly by nitrogen starvation. Twodimensional gel electrophoresis (2D-E) was performed, coupled with mass spectrometry analysis (MS) of spots displaying differential abundance. Similar approaches had been previously used to successfully determine the effects of breeding selection in plants and, very recently, in the nonoleaginous microalgae C. reinhardtii $[29,30]$. In our study, we identified proteins whose abundance was regulated by nitrogen starvation and whose abundance was different between the S2M2 mutant strain and the WT strain. By compiling these results, we were able to select a set of proteins that are 
103 regulated by nitrogen starvation in different way between the two strains. These proteins are good 104 candidates to conduct further investigations.

105 


\section{Materials and methods}

\section{Strains and growth conditions}

Tisochrysis lutea CCAP 927/14 wild type strain (WT) was purchased from the Culture Center of Algae and Protozoa (CCAP, Oban, Skotland). A mutant strain accumulating twice the amount of neutral lipids (S2M2) (CCAP926/14) was previously obtained after two steps of UV mutation and

111 cytometric selection [28]. Axenic WT and S2M2 strains were maintained in photoautotrophic batch 112 cultures in Walne's medium [31]. Starter cultures were grown in the same broth with continuous 113 illumination $\left(100 \mu \mathrm{mol}+/-5\right.$ photons $\left.\mathrm{m}^{-2} \mathrm{~s}^{-1}\right)$ to medium growth phase $\left(\mathrm{C}=12.6+/-1 \times 10^{6} \mathrm{cell}^{\mathrm{m}} \mathrm{mL}^{-1}\right)$.

114 For each strain, three flasks containing $1.5 \mathrm{~L}$ of $0.2 \mu \mathrm{M}$ filtered autoclaved sea water were inoculated at $0.3 \times 10^{6}$ cell. $\mathrm{mL}^{-1}$. Nutritive elements consisted of modified Walne's medium with a nitrate

116 concentration of $0.12 \mathrm{mM}$ instead of $1.2 \mathrm{mM}$. Growth in batch mode was conducted at $20^{\circ} \mathrm{C}$, with a constant continuous light irradiance of $100 \mu \mathrm{mol} \cdot \mathrm{m}^{-2} \cdot \mathrm{s}^{-1}$ and $\mathrm{CO}_{2}$-enriched bubble aeration. All experiments were carried out in triplicate.

Algae concentrations were measured daily by cell count in a Malassez counting chamber.

120 Particulate Nitrogen (QN) and Carbon (QC) were estimated by filtering a given volume of cells on 121 precombusted $25 \mathrm{~mm} \mathrm{GF/C} \mathrm{filters} \mathrm{(Whatman,} 1.2 \mu \mathrm{m}$ ). The filters were then dried for 24 hours at $70^{\circ} \mathrm{C}$ 122 and further analysed using a CN Elemental Analyzer (Flash 2000, Thermoscientific). Residual N and P in filtrates were assayed by DIONEX ion-chromatography (AS9-HC column).

\section{Lipid accumulation}

125 Lipid accumulation was analysed by the Nile red staining method [32]. One $\mathrm{mL}$ of culture was 126 stained with $2 \mu \mathrm{L}$ of Nile red diluted at $250 \mu \mathrm{g} \cdot \mathrm{mL}^{-1}$ in acetone. The mix was vortexed and incubated 127 for 5 minutes. Stained algae cells were excited at $480 \mathrm{~nm}$ and their total fluorescence intensity 128 detected at the 525-580 nm emission waveband using a Tecan Saphir II TM spectrofluorimeter (Tecan 129 Austria $\mathrm{GmbH}$, Grödig, Salzburg, Austria). Indices of relative fluorescence per cell were calculated to 130 estimate cell lipid concentration.

131 A flow cytometric analysis after Nile red staining was conducted on a BD Accuri TM C6 Flow 132 Cytometer. For each culture, 30,000 events were analysed daily and Nile red staining was analyzed 133 on FL2 (488-585 nm) detector. An Olympus BH2-RFCA microscope equipped with an Olympus light 
source for excitation was used to observe cells after Nile red staining. Native and fluorescence images were acquired using a CCD camera (Qimaging RETIGA 2000R).

\section{Protein extraction}

For the proteomic study, $400 \mathrm{~mL}$ of mid-exponential phase (Day 2) and $400 \mathrm{~mL}$ of end growth phase (Day 5) cultures were centrifuged at $2,500 \times \mathrm{g}$ for $20 \mathrm{~min}$ at $5^{\circ} \mathrm{C}$. Pellets were pooled and washed in $0.3 \mathrm{M}$ sucrose then quickly frozen at $-80^{\circ} \mathrm{C}$.

For each condition, total proteins were extracted from frozen cell pellets using a modified version of the protocol by Lee et al. [33]. Briefly, $1 \mathrm{~mL}$ trizol reagent was added to the pellets and pulse sonicated using a Vibra-Cell囚 75022 sonicator (Bioblock, Illkirch, France) in an ice bath for $3 \mathrm{~min}$ in the presence of a protease inhibitor (cOmplete tablets, Roche Diagnostics, Mannheim, Germany). Then, $200 \mu \mathrm{l}$ of chloroform were added to the cell lysate before shaking and centrifugation at $12,000 \times$ $g$ for $10 \mathrm{~min}$ at $4^{\circ} \mathrm{C}$. The hydrophilic phase was removed and $300 \mu \mathrm{L}$ ethanol added to dissolve the reddish bottom layer. The mixtures were centrifuged at $16,000 \times g$ for $10 \mathrm{~min}$ and the supernatants mixed with one volume of $20 \%$ trichloroacetic acid (TCA) and $0.14 \% \beta$-mercaptoethanol, in cold acetone. After being left overnight, proteins were precipitated at $-20^{\circ} \mathrm{C}$, the mixtures were centrifuged at $16,000 \times g$ for $10 \mathrm{~min}$ at $4^{\circ} \mathrm{C}$. The pellets were washed with cold acetone then resuspended in buffer containing $6 \mathrm{M}$ urea, $2 \mathrm{M}$ thio-urea, 4\% CHAPS and 2\% Bio-Lyte 3/10.

Each extract was analysed on analytic 2-DE gels using the adapted O'Farell protocol [34]. A pH gradient of 4-7 was chosen for isoelectric focusing (IEF). The second-dimension electrophoresis was performed on $12 \%$ SDS polyacrylamide gels to optimize the separation of proteins with a molecular weight ranging from 10 to $120 \mathrm{kDa}$. Aliquots containing $30 \mu \mathrm{g}$ of protein for analytic gels and $300 \mu \mathrm{g}$

156 for preparative gels were purified with a 2D Clean-up kit (GE Healthcare) and resuspended in $330 \mu \mathrm{L}$ rehydration buffer containing $6 \mathrm{M}$ urea, $2 \mathrm{M}$ thio-urea, 4\% CHAPS, 2\% Bio-Lyte 3/10, 0.01\% bromophenol blue, $3.3 \mathrm{mM}$ tributylphosphine, and 5\% DTT. After $18 \mathrm{~h}$ of active rehydration of dry immobilized pH gradient (IPG) strips, linear pH 4-7 (Bio-Rad, Marnes-la-Coquette, France), at $50 \mathrm{~V}$,

160 IEF was performed using the Bio-Rad Protean IEF Cell at 66,000 V.h. The strips were next treated 161 with buffer containing $6 \mathrm{M}$ urea, $2 \%$ SDS, $0.05 \mathrm{M}$ Tris-HCl pH 8.8, 30\% glycerol and supplemented 
163 iodoacetamide. Finally, proteins were visualized by the silver staining method for analytic gels and Bio-

164 Safe colloidal Coomassie blue (Bio-Rad, Marnes la Coquette, France) for preparative gels. Two

165 technical replicates were made for each of the twelve extracts.

\section{Image and statistical analysis}

Images of analytic gels were recorded on a Bio-Rad GS800 densitometer. Gels were analyzed with the Progenesis SameSpots, version 3.0, software (Nonlinear Dynamics Ltd., Newcastle, United Kingdom). The quality of the gels was verified using the quality control (QC) of the software. The vector alignment tool of SameSpots Workflow was employed for an automatic pixel level geometric alignment of the gels, followed by manual corrections. The background-corrected abundance of each spot was calculated, and the abundance ratio was determined by dividing the sample abundance by the reference abundance. Spot volumes were normalized to calibrate data between different sample runs, and normalized spots were then analysed statistically using the statistics module in SameSpots. Principal component analysis (PCA) was used to separate the gels according to variations in the normalized volume of the spots. ANOVAs were performed to assess significant differences between the strains and the phases (exponential and stationary on Fig. 5). Significant over-abundant spots were detected at a $5 \%$ significance level $(p$-value $<0.05)$. Finally, these spots were refined using a $q$ value $<0.05$ to discard false positives, a power $>0.8$ to ensure reproducibility among gels of with the same conditions and a fold number $>2$ for the biological significance.

\section{LC-MS/MS}

Selected spots were excised manually, washed with $100 \mu \mathrm{L} 25 \mathrm{mM} \mathrm{NH}_{4} \mathrm{HCO}_{3}$, followed by $100 \mu \mathrm{L}$ of $50 \%$ acetonitrile in $25 \mathrm{mM} \mathrm{NH}_{4} \mathrm{HCO}_{3}$. Proteins were then reduced by incubation with $10 \mathrm{mM}$ DTT (1 h, $57^{\circ} \mathrm{C}$ ), and alkylated with $55 \mathrm{mM}$ iodoacetamide ( $45 \mathrm{~min}$ at room temperature). Gel spots were

186 further washed as described above. The proteins were digested overnight at $37^{\circ} \mathrm{C}$ by addition of $10-20$ $\mu \mathrm{L}$ trypsin (12.5 ng. $\mu \mathrm{L}^{-1}$ in $25 \mathrm{mM} \mathrm{NH}_{4} \mathrm{HCO}_{3}$; modified trypsin purchased from Promega, Madison, WI).

188 The resulting peptide mixture was acidified by the addition of $1 \mu \mathrm{L}$ of an aqueous solution of formic acid $(1 \% \mathrm{vol})$, stored at $-20^{\circ} \mathrm{Cand}$ used for analysis without any further preparation. 
Nanoscale capillary liquid chromatography-tandem mass spectrometry analyses of the digested 192 proteins were performed using an Ultimate 3000 RSLC system (Dionex) coupled with a LTQ-Orbitrap

193 VELOS mass spectrometer controlled by the X-Calibur version 2.1 software (Thermo Scientific). 194 Chromatographic separation was conducted on a reverse-phase capillary column (Acclaim Pepmap $195 \mathrm{C} 182 \mu \mathrm{m} \mathrm{100A}, 75-\mu \mathrm{m}$ i.d. $\times 15-\mathrm{cm}$ length, Thermo- Scientific) at a flow rate of $300 \mathrm{~nL} . \mathrm{min}^{-1}$. Mobile 196 phase $\mathrm{A}$ was composed of $99.9 \%$ water and $0.1 \%$ formic acid); mobile phase B of $90 \%$ acetonitrile 197 and $0.08 \%$ formic acid. The gradient consisted of a linear increase from $4 \%$ to $45 \%$ of $B$ in 30 min 198 followed by a rapid increase to $70 \%$ within $1 \mathrm{~min}$.

199 Full MS scans were acquired at high resolution (FWMH 30,000) on the Orbitrap analyzer, while 200 collision-induced dissociation (CID) MS/MS spectra were recorded on the five most intense ions in the 201 linear LTQ traps. Dynamic exclusion was employed within $60 \mathrm{~s}$ to prevent repetitive selection of the 202 same peptide.

\section{Databases searches}

Raw data collected during LC-MS/MS analyses were processed into MGF (Mascot Generic Format) files by using Proteome Discoverer version 1.7 (Thermo Scientific) and further searched against databases using MASCOT Server version 2.2 (Matrix Science). One search was performed against a concatenated algae database (99898 sequences) built from UniProt release 2012_01 (January 21, 2012) after restriction to the following taxonomies: Isochrysis, Emiliania huxleyi, Phaeodactylum tricornutum, Thalassiosira pseudonana, Chlamydomonas reinhardtii, Ostreococcus 212 database search was done against the six-frame translated de novo assembled Tisochrysis lutea transcriptome. This transcriptome was recently obtained and assembled from raw data accessible in

214 SRR824147 in the National Center for Biotechnology Information [35]. One missed trypsin cleavage was allowed. Carbamidomethylation of cysteines was set as a fixed modification, and oxidation of 216 methionine as a variable modification. The mass tolerances in MS and MS/MS were set to $5 \mathrm{ppm}$, 217 and a mass tolerance of $0.0005 \%$ and 0.5 Da respectively. Protein identifications were validated when 218 a minimum of two unique peptides were matched in their sequence, with a MASCOT individual ion score above the threshold corresponding to a p-value of 0.05 . The exponentially modified protein 
220 abundance index (emPAl) was calculated for each scoring protein [35] and the highest emPAl was 221 selected as the most abundant protein of the spot.

222 The coding sequence (CDS) that contained peptides identified by MS were blasted (BLAST-X) 223 against non-redundant protein sequences database (nr) from NCBI with "algae" as the filter. Molecular 224 weight and pl were computed on the EXPASY website (http://web.expasy.org/compute_pi). Domains 225 and motifs were sought using Conserved Domain Database [36] and PRODOM [37] software, 226 successively. The presence of signal peptides and location of membrane domains were predicted by 227 Phobius [38] and SOSUI [39] software. 


\section{Growth and lipid accumulation}

231

232

In most microalgae, the amount of neutral lipids increases under nitrogen starvation [40-43]. Neutral lipids accumulate in lipid droplets, whose size and number increase under nitrogen starvation $[23,44-48]$. In this study, the detailed time course of growth and neutral lipid accumulation were assessed in nitrogen-limited batch cultures of Tisochrysis lutea wild type and the mutant stain S2M2, selected for lipid over-accumulation. To obtain nitrogen-limiting conditions, a broth poor in nitrogen was used. The growth patterns of the two strains showed some similarity (Fig. 1). The stationary phase was reached in four days, and maximal cell concentrations were quite different between the strains $\left(3.7 \times 10^{6}\right.$ cell. $\mathrm{mL}^{-1}$ for WT, and $3.0 \times 10^{6}$ cell. $\mathrm{mL}^{-1}$ for S2M2) (Fig. 1). Dissolved nitrogen (N) and phosphorus $(P)$ concentrations in the extra-cellular medium were monitored over the five first days of the culture (Fig. 2). They constitute the two major substrates for microalgae. While the amount of $P$ decreased slightly, the amount of $\mathrm{N}$ decreased drastically to reach zero $\mu \mathrm{Mol} . \mathrm{L}^{-1}$ at day 3 . The C:N ratios of cells increased from day 2 to day 4 (Fig. 2) confirming the nitrogen limitation [49].

Overall lipid accumulation was followed using Nile red fluorescence. In both strains, total Nile red fluorescence increased until day 6 (see supplementary data). In order to take account the increase of cell concentration, the index of fluorescence per cell was calculated. After two days, it increased in both strains until the end of the experiment (Fig. 1). This confirms that the increase of neutral lipid accumulation was correlated with nitrogen limitation, as previously shown for Isochrysis galbana [50]. Surprisingly, this increase did not continue so highly in the wild-type strain during the stationary phase, unlike in the S2M2 strain, where the amount of neutral lipids continued to increase until the end of the experiment. At day 2, the mean of Nile red fluorescence index of S2M2 culture was 1.6 fold higher than that of WT, by day 4 it was 3.2 fold higher and by day 6 it was 5.4 fold higher. Cytometric analysis were performed to measure the individual cellular Nile red fluorescence of samples of 30,000 cells. The averages of cells fluorescence suggested an increase of lipid concentration per cell during the experiment for both strains. In addition, the averages of cell fluorescence inside each population were greater in S2M2 than in WT strain. These results are in accordance with the results of overall fluorescence measured with the spectrophotometer (see above). On other point, the distributions of Nile red fluorescence per cell measured by flow cytometry were analysed on density histograms (see 
supplementary data). They revealed that WT and S2M2 populations followed normal distributions of

260 Nile red fluorescence. This indicates that lipid accumulation is homogenous inside each one of both 261 populations. In other words, the differences of lipid accumulation it is not caused by the effect of a sub262 population but concerns the entire populations. Microscopic observations of cells after Nile red 263 staining at day 5 showed that the number of lipid droplets (LD) was about two per cell in WT cells and 264 between 3 and 6 in S2M2 cells (Fig. 3). Droplet sizes appeared larger in S2M2 cells than in WT cells. 265 These results are in accordance with the spectrofluorometic and cytometric analysis that showed 266 higher Nile red fluorescence in S2M2 strain. Because the effect of nitrogen starvation on lipid 267 accumulation is greater in strain S2M2, we propose that this S2M2 strain would make a good model to 268 study the metabolism and accumulation of neutral lipids in Tisochrysis lutea in the same manner as a 269 starchless mutant was used for the study of lipid accumulation in Chlamydomonas reinhardtii $[13,47]$.

\section{Comparative proteomics and functional classification}

Proteomics was applied for the two strains (WT and S2M2) i) at exponential phase (Day 2) when neutral lipid accumulation was low and dissolved nitrogen still available, ii) at the beginning of 274 stationary phase (Day 5) when neutral lipid accumulation was high and absence of dissolved nitrogen limited the growth. The aim was to reveal the proteins whose abundance is regulated by nitrogen starvation, and the proteins whose abundance is different between the two strains. Two-dimensional electrophoresis analyses were performed. This robust technique was described as a valuable tool to separate with good resolution and quantify in the same time major proteins in non-model species. For each of the four conditions, biological triplicates and technical duplicates were performed. About 1850 spots were visualized on each of the 2-DE gels (Fig. 4). Principal component analysis of the complete dataset (24 gels) clearly showed four distinct clusters of gels corresponding to the four experimental conditions (Fig. 5). This suggests a modification of the proteome of the mutant strain, as well as induction of specific proteomes for both strains during $\mathrm{N}$-limited batch stationary phase.

Statistical analysis of normalized volume of each spot on each gel were performed to select spots 286 with difference in spot volume ( $p$ value<0.05). Considering the large number of tests (1850 spots), 287 false discovery rate (FDR) were measured and significant positives were selected with a FDR q-value 288 threshold of $5 \%$. In the WT strain, 19 spots were up accumulated at day 5 (vs. day 2) and 33 were 
down accumulated. In the S2M2 strain, 4 spots were up accumulated at day 5 (vs. day 2) and 24 were down accumulated. In addition, 42 spots have a difference of intensity between the two strains at day

2912 (18 down and 24 up-expressed in S2M2 vs WT) and 73 at day 5 (39 down and 34 up-expressed in S2M2 vs WT).

57 spots showing significant differences on analytical gels (Fig. 4) were sufficiently concentrate for been visualized on preparative gels stained with Coomassie blue. They were picked and analysed by MS. Whereas searching against Uniprot databases only allowed the identification of six spots, searching against the $T$. lutea transcriptome led to the identification of 48 spots corresponding to 40

297 different single transcripts. This difference arose because sometimes more than one spot was affiliated to the same transcript; a result consistent with the observations of Guarnieri et al. [21]. The identification of proteins by comparing the mass profiles with in silico data could be done much more efficiently using the home-made transcriptome of Tisochrysis lutea than using public data on other algae species. Nine spots failed to produce any unambiguous MS identification.

Manual annotation of translated transcripts was performed to obtain functional insights on identified sequences. BLAST-X and domain research allowed assignment of putative functions for 27 proteins, classified into nine metabolic groups (Tab.1). Six other proteins had a homolog in other algae species but their function remains unknown (Tab.1). They were named "conserved unknown proteins". Among these six proteins, one has a MORN-repeat domain and three have a NAD-Rossmann-fold domain including one that has a FabG domain. To date, seven proteins have no homolog in public databases. Although a C1-peptidase domain could be found for one of them and a methyltransferase (MTase) domain was found for another, their functions remain unknown. For transcripts whose CDS was clearly identified, theoretical molecular weight and pl (MW / pl) were quite similar to experimental MW / pl on 2-DE gels (Tab.1).

\section{Proteins affected by nitrogen starvation}

313 About $2.5 \%$ of the analysed WT proteome was affected by nitrogen starvation. Numerous 314 metabolic pathways were affected, but the abundance of the stress proteins identified in this study 315 (SuperOxide Dismutase (SOD), Protein Disulfide Isomerase (Pdi), Clp protease and Heat Shock 316 Protein Hsp60) was not affected. This may because the sampling under nitrogen starvation 317 corresponded to an early step of stationary phase when the growth was limited by nitrogen starvation, 318 but cells had not yet triggered a stress response. This suggests that the comparative proteomic 
analysis shows the effects of a halt in growth due to nitrogen starvation but not the response to the stress that could occur later in the stationary phase.

Thirteen proteins identified in this study were less abundant during nitrogen starvation (Tab. 2). These include three plastidal ribosomal proteins, the CF1 beta subunit of ATP synthase and the two subunits of rubisco (RuBisCo Large subunit and Small subunit (RBCL and RBCS)) involved in the first major step of carbon fixation. RBCL and RBCS co-accumulated in the same way during nitrogen starvation and their ORFs were located on the same transcript of $T$. lutea. These two ORFs are located on the same operon in prymnesiophyte plastids [51]. This suggests that transcriptional regulation of the whole operon could occur, leading to the regulation of protein abundance during stationary phase. Three enzymes involved in the pigment biosynthetic process were also downaccumulated at stationary phase including (1) uroporophyrogen decarboxylase (fold $=3.1$ ) and coproporphyrinogen III oxidase (fold $=2.1$ ), successively involved in the porphyrin and chlorophyll metabolic pathways; and (2) geranylgeranyl pyrophosphate synthetase (GGPP synthase) (fold $=2.4$ ), which plays a role in the level of carotenogenesis. Two proteins of lipid metabolism were downaccumulated by nitrogen starvation, including the plastid beta-ketoacyl-ACP reductase (FabG) (fold = 2.5 ) and the "FabG domain-containing conserved unknown protein" (fold $=4.7$ ) (Tab. 6). FabG catalyzes the NADPH-dependent reduction of beta-ketoacyl-ACP substrates to beta-hydroxyacyl-ACP products, the first reductive step in the elongation cycle of fatty acid biosynthesis. The "FabG domaincontaining conserved unknown protein" was down-accumulated in same manner but its function remains more uncertain.

To resume, nitrogen deprivation induced a decrease of proteins involved in: i) carbon fixation 340 (RBCL and RBCS), ii) the pigment biosynthetic process (GGPP synthase, UPIII decarboxylase and 341 CPIII oxidase), iii) energetic metabolism (ATP synthase), and iv) translation processes (3 ribosomal 342 proteins) and v) fatty acid metabolism (FabG and FabG domain-containing conserved unknown 343 protein). These results are in good agreement with previous transcriptomic and proteomic studies on 344 the chlorophyceae C. reinhardtii $[11,48,52-54]$, in the eustigmatophyte Nannochloropsis sp., the 345 chlorophyte Micractinium pusillum, and the diatom Phaeodactylum tricornutum [15-18,52,55]. All 346 these results suggest that a halt in growth in response to nitrogen starvation causes similar decreases 347 in several biological activities in most microalgae. Longworth et al. interpreted these biological 348 responses as an entry into a type of dormancy of the microalgae [52] 
Three proteins up-accumulating during nitrogen starvation were identified (Tab. 3). These include acetyl-CoA/propionyl-CoA carboxylase (ACCase) (fold $=2.9$ ), which plays a major role in the first

351 steps of fatty acid biosynthesis by catalyzing the carboxylation of acetyl-CoA to produce malonyl-CoA.

352 Its role in fatty acid regulation has been demonstrated for the Isochrysidales [26,27]. Another of the 353 proteins has a strong homology with the coccolith scale associated protein (CSAP1) of Pleurochrysis 354 carterae and with an unknown predicted protein of Phaeodactylum tricornutum. To our knowledge, the 355 function of this protein is unknown, but PRODOM software identified a pyridoxal-phosphate-dependent 356 decarboxylase domain specific to group II decarboxylase, which includes aromatic-L-amino-acid 357 decarboxylases, tyrosine decarboxylase and histidine decarboxylase. Four isoforms of CSAP-1 of the 358 same size increased by 6.2 fold in relative abundance during nitrogen starvation (spot 3951 on Fig.4). 359 CSAP-1 contains a DDC-GAD-HDC-YDC decarboxylase domain and could be involved in the 360 decarboxylation of aromatic-L-amino-acid tyrosine or histidine. However, its function remains unclear. 361 Homologs were found in the prymnesiophyte Pleurochrysis carterae transcriptome and in the $P$. 362 tricornutum genome, but not in other algae species, even in other prymnesiophyte transcriptomes. 363 RNAseq analysis of $P$. tricornutum showed an up-regulation of this protein under nitrogen starvation 364 and Valenzuela et al. speculated that this protein might play a role in inorganic carbon homeostasis 365 [18]. Because this protein is among those that are most up-accumulated under nitrogen deprivation, a 366 functional analysis should be made to identify its molecular and cellular functions. Four isoforms of 367 Coccolith Scale Associated Protein-1 (CSAP1) of same size were increased by 6.2 fold in relative 368 abundance during nitrogen starvation (spot 3951 on Fig. 4). They probably correspond to different 369 post-translational forms of the same protein. Two closed isoforms of the periplasmic L-amino acid 370 oxidase (PAAOx) of the same size increased by 8.2- to 4.3-fold in relative abundance with nitrogen 371 deprivation (spots 1108 and 1144 on Fig.4 A ) (Tab. 3). Vallon et al. defined PAAOx as a scavenger of 372 ammonium from extracellular amino acids in C. reinhardtii [56]. In silico analysis of the coding region 373 revealed the presence of a signal peptide and transmembrane region. This suggests that this enzyme 374 is anchored to the membrane and transported to the plasma membrane. This protein could be 375 involved in the access of extracellular organic nitrogen in response to nitrogen deprivation. 


\section{Proteins affected by strain selection}

The abundances of 33 spots identified by MS were found to differ between the two strains, whatever the phase of culture (Tab. 4 and Tab. 5). Five proteins involved in stress response were

380 identified. The ATP-binding subunit of Clp protease and the two chaperones Hsp60 and Hsp70 were 381 less abundant in the S2M2 strain, whereas superoxide dismutase Ni-type (SOD) and disulfide 382 isomerase (Pdi) were more abundant. Because UV mutations and cytometric sorting generate cellular stress, we suggest that there was selection for cells acclimated to stress in the S2M2 population. Five identified proteins involved in respiration, photosynthesis and glycolysis were affected by $\mathrm{N}$ deprivation, suggesting an overall reorganization of the energetic metabolism in the selected S2M2 strain: two glyceraldehyde 3-phosphate dehydrogenases (GAPDH), which are key enzymes of glycolysis, and the core 1 subunit of ubiquinol:cytochrome c oxidoreductase involved in the mitochondrial respiratory chain were up-accumulated in S2M2 strain,. One ATP synthase and two proteins of photosynthesis (the chloroplast ferredoxin NADP reductase and the ferredoxin) were less abundant. The ferredoxin is the last protein of photosystem I and serves as a substrate for the chloroplast ferredoxin NADP reductase.

Finally, two Glycoside Hydrolases including GH16 (spots 1221, 1238, 1241 and 1215 on Fig. 4) and GH30 (spots 1074 and 1078 on Fig. 4) were abundant in the S2M2 strain, but were not detected in the WT strain (Tab. 6). For these two proteins, several spots with the same molecular weight were identified, suggesting post-translational modifications. The analysis of coding regions revealed a transmembrane region for each one of these enzymes and a signal peptide for $\mathrm{GH} 30$, suggesting it had a specific cellular localisation. Glycoside hydrolases are a widespread group of enzymes that hydrolyze the glycosidic bond between two or more carbohydrates or between a carbohydrate and a noncarbohydrate moiety [57]. The GH16 and GH30 families are responsible for the degradation of many substrates and are well described on the carbohydrate-active enzymes (CAZy) database (http://www.cazy.org). Enzyme activities currently assigned within $\mathrm{GH} 30$ family include $\beta$-glucosidase, $\beta$-xylosidase and endo- $\beta-1,6$-glucanase [57,58]. Enzyme activities currently assigned within GH16 family include enzymes involved in the hydrolysis of storage carbohydrates, such as laminarinases, beta-agarase and endo-1,3-beta-glucanases. To our knowledge, the nature of storage and cell wall carbohydrates in $T$. lutea has never been clearly identified and the substrates of these two enzymes should be identified for more accurate conclusions. However, we suggest that the up-regulation of 
these two glycoside hydrolases would lead to a better availability of hydrolysable carbohydrates for glycolysis. Interestingly, two glyceraldehyde 3-phosphate dehydrogenase (GAPDHs) enzymes known to be mainly involved in glycolysis were more abundant in the S2M2 strain than the WT. Glycolysis is an important source of acetyl-CoA. Studies of starchless mutants of the green algae Chlamydomonas reinhardtii strongly suggested that the carbon flux between the biosynthesis of starch and triacylglycerides are interrelated and that the carbon sources for TAG biosynthesis could be largely derived from carbohydrates and acetyl-CoA metabolism [13]. In same way, our results suggest that the metabolism upstream of de novo fatty acid biosynthesis (carbohydrate catabolism and glycolysis) are determinant for the over production of lipids in S2M2 strain. Thus, like C reinhardtii, lipid accumulation in T. lutea could be closely related to carbohydrate metabolism [13].

\section{Proteins impacted by strain selection and nitrogen starvation}

We focused on six proteins whose abundance was similar between strains during exponential phase (i.e. when lipid accumulation was the same) and whose abundance was different at early stationary phase, when lipid accumulation was much higher in strain S2M2 than WT.

The two spots identified as a FabG (spot 3009) and "FabG domain-containing conserved unknown protein" (spot 2681) were down-accumulated in the WT strain upon nitrogen starvation, while their relative abundance remained constant in the S2M2 strain, suggesting the absence of regulation of these proteins here (Tab.6). The involvement of the "FabG domain-containing conserved unknown protein" in the fatty acid metabolism remains speculative but, surprisingly, this protein was regulated like FabG. 3-oxoacyl-(acyl-carrier-protein) reductase (FabG) catalyses the first reduction step of de novo fatty acid elongation. This process involves condensation of $\mathrm{C} 18: 1-\mathrm{CoA}$ with malonyl-CoA to form 3-ketoacyl-CoA, reduction of this 3-ketoacyl-CoA, dehydration of the resulting 3-hydroxyacyl-CoA and, finally, reduction of the trans-2,3-enoyl-CoA. Because the amount of neutral fatty acid increases in strain S2M2 at stationary phase but not in WT, we assume that the down-expression of these 431 proteins could be connected to the halt in of lipid accumulation in the WT strain. In strain S2M2, 432 neutral lipid accumulation continues during stationary phase, when these proteins are not down433 expressed. Because the regulation of protein spots was similar for both enzymes, this suggests that 434 regulation mechanisms could be at the same step for both homologues. In C. reinhardtii, some genes 435 involved in the build-up of TAGs were up-regulated during nitrogen starvation and perhaps driven by 
the transcription factor identified by Boyle et al [11]. In T. Iutea, regulation of FabG and "FabG domaincontaining conserved unknown protein" should be explored at transcriptional level.

PLAAOx (spots 1108 and 1144 on Fig.4) was strongly up-accumulated in the WT strain under nitrogen starvation (fold $=8.2$ and 4.3 ) but not detected in the S2M2 strain (Tab. 6). As previously stated, PLAAOx is involved in the access to extra-cellular organic nitrogen [56]. The lower abundance of this protein under nitrogen starvation in strain S2M2 could lead to a reduction of its capacity to access nitrogen from dissolved organic nitrogen. In this study, no difference in nitrogen accumulation was observed between the two strains until day 5. It would be interesting to examine the C:N ratio during the last days of stationary phase. The involvement of PLAAOx in lipid accumulation remains speculative, however.

CSAP1 (spot 3951 for CSAP1 on Fig. 4) was strongly up-accumulated in the WT strain under nitrogen starvation (fold $=6.2$ ), but was only slightly up-accumulated in the S2M2 strain and was much less abundant there than in the WT strain (fold $=6.0)($ Tab. 6). This observation could suggest that the mechanisms regulating the overproduction of this protein and PLAAOx during nitrogen starvation are partially reduced in the S2M2 strain. The function of CSAP1 in neutral lipid accumulation remains unclear and should be explored. However, this protein is probably involved in carbon homeostasis [18]. As mentioned above, the orientation of carbon into acetyl-CoA upstream of de novo fatty acid biosynthesis appears to be crucial for lipid metabolism. A difference in carbon homeostasis between the two strains during nitrogen starvation could lead to a reallocation of carbon for lipid metabolism Like the two glycoside hydrolases previously identified in this study, the CSAP1 provides a good candidate for further investigations into lipid accumulation under nitrogen starvation.

\section{Conclusion}

To our knowledge, this paper is the first comparative proteomic analysis in a microalgae of biotechnological interest that makes a comparative analysis of nitrogen stress between a wild type

460 strain and a selected mutant. Mutant and wild type strains of Tisochrysis lutea were analysed during growth phase and during early stationary phase in batch cultures limited by nitrogen. The results

462 highlight proteins differentially expressed between the two strains and regulated during nitrogen starvation. A set of proteins was selected for been potentially involved directly or indirectly in the up-

464 accumulation of lipids in the selected strain. This group notably includes proteins involved in carbon homeostasis, fatty acid biosynthesis and carbohydrate catabolism. 
Fig. 1 : (A) Growth and (B) neutral lipid accumulation of Tisochrysis lutea WT and S2M2 strains in a batch culture limited by nitrogen. Cultures were done in triplicate. Cell concentations and nile red fluoresence index per cell were calculated daily.

Fig. 2 : (A) Dissolved Inorganic Nitrogen and Phosphorus in WT and S2M2 cultures. (B) C:N ratio were calculated from particulate carbon and nitrogen analysis. Means and standart errors were calculated from biological replicates and indicated on the graphs.

Fig. 3 : Microscopic observations of Tisochrysis lutea WT (columns A and B) and S2M2 (C and D) strains. Cells were observed by transmissive optic microscopy and epifluorescence microscopy after Nile red straining. Sizes and number of lipid droplets were revealed by Nile red coloration of neutral lipids.

Fig. 4 : 2-DE of whole cell proteoms of Tisochrysis lutea WT (A) and S2M2 (B) strains at early stationnary phase of nitrogen limited batch cultures. Proteins of both strains at exponential and early stationary phases were extracted. Biological triplicates and technical duplicates were. $30 \mu \mathrm{g}$ of whole cell proteins were separed on $\mathrm{pH}$ 4-7 gradient and $12 \%$ polyacrylamide SDS gel, and revealed by silver staining. 24 gels gels were include for image and statistical analysis. Identified spots by MS-MS are localized on the gels.

487 Fig. 5 : Principal component analysis performed on the complete data set of the 24 2-DE gels 488 according to variations in the normalized volume of the 1850 spots.

\section{Acknowledgements}

We are very grateful to Mathilde Joint and Marija Pavlovic (INRA, UR1268 - BIBS platform, 493 Nantes) for their excellent technical assistance with the mass spectrometry analysis, and Ewa 494 Lukomska for CN Elemental and and ion-chromatography analysis. This work was partly funded by 
495 region of Pays de Loire "Nouvelle équipes, nouvelles thématique" program and by the 496 Agence National de la Recherche, Facteur 4 project. There are any non-financial competing 497 interests. 
499

500

501

502

503

504

505

506

507

508

509

510

511

512

513

514

515

516

517

518

519

520

521

522

523

524

525

526

527

528

529

530

531

532

533

534

535

536

537

538

539

540

541

542

543

544

545

[1] Khozin-Goldberg I, Cohen Z. Unraveling algal lipid metabolism: Recent advances in gene identification. Biochimie 2011;93:91-100.

[2] Guschina IA, Harwood JL. Lipids and lipid metabolism in eukaryotic algae. Prog Lipid Res 2006;45:160-86.

[3] Harwood JL, Guschina IA. The versatility of algae and their lipid metabolism. Biochimie 2009;91:679-84.

[4] Moellering ER, Miller R, Benning C. Molecular Genetics of Lipid Metabolism in the Model Green Alga Chlamydomonas reinhardtii. Lipids Photosynth 2010:139-55.

[5] Hu Q, Sommerfeld M, Jarvis E, Ghirardi M, Posewitz M, Seibert M, et al. Microalgal triacylglycerols as feedstocks for biofuel production: perspectives and advances. Plant $\mathrm{J}$ Cell Mol Biol 2008;54:621-39.

[6] L L H i , Sialve B, Steyer J-P, Bernard O. Life-Cycle Assessment of Biodiesel Production from Microalgae. Environ Sci Technol 2009;43:6475-81.

[7] Petkov G, Ivanova A, Iliev I, Vaseva I. A critical look at the microalgae biodiesel. Eur J Lipid Sci Technol 2012;114:103-11.

[8] Solovchenko AE. Physiological role of neutral lipid accumulation in eukaryotic microalgae under stresses. Russ J Plant Physiol 2012;59:167-76.

[9] Me ch t SS K p t J Liu B Sh w J W k t J . T G Y u' e it! Ch m y m as a reference organism for understanding algal triacylglycerol accumulation. Curr Opin Biotechnol 2011.

[10] Gardner RD, Lohman E, Gerlach R, Cooksey KE, Peyton BM. Comparison of CO2 and bicarbonate as inorganic carbon sources for triacylglycerol and starch accumulation in Chlamydomonas reinhardtii. Biotechnol Bioeng 2013;110:87-96.

[11] Boyle NR, Page MD, Liu B, Blaby IK, Casero D, Kropat J, et al. Three Acyltransferases and a Nitrogen Responsive Regulator Are Implicated in Nitrogen Starvation-Induced Triacylglycerol Accumulation in Chlamydomonas. J Biol Chem 2012.

[12] Fan J, Yan C, Andre C, Shanklin J, Schwender J, Xu C. Oil accumulation is controlled by carbon precursor supply for fatty acid synthesis in Chlamydomonas reinhardtii. Plant Cell Physiol 2012;53:1380-90.

[13] Li Y, Han D, Hu G, Dauvillee D, Sommerfeld M, Ball S, et al. Chlamydomonas starchless mutant defective in ADP-glucose pyrophosphorylase hyper-accumulates triacylglycerol. Metab Eng 2010;12:387-91.

[14] Cadoret J-P, Garnier M, Saint-Jean B. Chapter Eight - Microalgae, Functional Genomics and Biotechnology. In: Gwenaël Piganeau, editor. Adv. Bot. Res., vol. Volume 64, Academic Press; 2012, p. 285-341.

[15] Tran N, Park J, Lee C. Proteomics analysis of proteins in green alga Haematococcus lacustris (Chlorophyceae) expressed under combined stress of nitrogen starvation and high irradiance. ENZYME Microb Technol 2009;45:241-6.

[16] Liang C, Cao S, Zhang X, Zhu B, Su Z, Xu D, et al. De Novo Sequencing and Global Transcriptome Analysis of Nannochloropsis sp. (Eustigmatophyceae) Following Nitrogen Starvation. BioEnergy Res n.d.:1-12.

[17] Li Y, Fei X, Deng X. Novel molecular insights into nitrogen starvation-induced triacylglycerols accumulation revealed by differential gene expression analysis in green algae Micractinium pusillum. Biomass Bioenergy 2012;42:199-211.

[18] Valenzuela J, Mazurie A, Carlson RP, Gerlach R, Cooksey KE, Peyton BM, et al. Potential role of multiple carbon fixation pathways during lipid accumulation in Phaeodactylum tricornutum. Biotechnol Biofuels 2012;5:40. 
[19] Radakovits R, Jinkerson RE, Fuerstenberg SI, Tae H, Settlage RE, Boore JL, et al. Draft genome sequence and genetic transformation of the oleaginous alga Nannochloropis gaditana. Nat Commun 2012;3:686.

[20] Dong H-P, Williams E, Wang D, Xie Z-X, Hsia R, Jenck A, et al. Responses of Nannochloropsis oceanica IMET1 to long-term nitrogen starvation and recovery. Plant Physiol 2013.

[21] Guarnieri MT, Nag A, Smolinski SL, Darzins A, Seibert M, Pienkos PT. Examination of triacylglycerol biosynthetic pathways via de novo transcriptomic and proteomic analyses in an unsequenced microalga. PloS One 2011;6:e25851.

[22] Bendif EM, Probert I, Hervé A, Billard C, Goux D, Lelong C, et al. Integrative Taxonomy of the Pavlovophyceae (Haptophyta): A Reassessment. Protist 2011.

[23] Eltgroth ML, Watwood RL, Wolfe GV. Production and cellular localization of neutral long chain lipids in the haptophyte algae Isochrysis galbana and Emiliania huxleyi. J Phycol 2005;41:1000-9.

[24] Feng D, Chen Z, Xue S, Zhang W. Increased lipid production of the marine oleaginous microalgae Isochrysis zhangjiangensis (Chrysophyta) by nitrogen supplement. Bioresour Technol 2011;102:6710-6.

[25] Flynn K, Garrido J, Zapata M, Öpik H, Hipkin C. Changes in fatty acids, amino acids and carbon/nitrogen biomass during nitrogen starvation of ammonium- and nitrategrownIsochrysis galbana. J Appl Phycol 1992;4:95-104.

[26] LIVNE A, SUKENIK A. Lipid Synthesis and Abundance of Acetyl CoA Carboxylase in Isochrysis galbana (Prymnesiophyceae) Following Nitrogen Starvation. Plant Cell Physiol 1992;33:1175-81.

[27] Sukenik A, Livne A. Variations in Lipid and Fatty Acid Content in Relation to Acetyl CoA Carboxylase in the Marine Prymnesiophyte Isochrysis galbana. Plant Cell Physiol 1991;32:371-8.

[28] Bougaran G, Rouxel C, Dubois N, Kaas R, Grouas S, Lukomska E, et al. Enhancement of neutral lipid productivity in the microalga Isochrysis affinis Galbana (T-Iso) by a mutation-selection procedure. Biotechnol Bioeng 2012;109:2737-45.

[29] Devouge V, Rogniaux H, Nési N, Tessier D, Guéguen J, Larré C. Differential Proteomic Analysis of Four Near-Isogenic Brassica napus Varieties Bred for their Erucic Acid and Glucosinolate Contents. J Proteome Res 2007;6:1342-53.

[30] Choi Y-E, Hwang H, Kim H-S, Ahn J-W, Jeong W-J, Yang J-W. Comparative proteomics using lipid over-producing or less-producing mutants unravels lipid metabolisms in Chlamydomonas reinhardtii. Bioresour Technol 2013.

[31] P.R Walne. Experiments in the large scale culture of the larvae of Ostrea edulis. L. FISH INVEST MINISTR. 1996.

[32] Greenspan P, Mayer E, Fowler S. Nile Red - a Selective Fluorescent Stain for Intracellular Lipid Droplets. J Cell Biol 1985;100:965-73.

[33] Lee F, Lo S. The use of Trizol reagent (phenol/guanidine isothiocyanate) for producing high quality two-dimensional gel electrophoretograms (2-DE) of dinoflagellates. J Microbiol METHODS 2008;73:26-32.

[34] O'F e PH. High e uti tw -dimensional electrophoresis of proteins. J Biol Chem 1975;250:4007-21.

[35] Carrier G, Garnier M., Le Cunf L, Bougaran G, Probert I, de Vargas C, et al. Comparative transcriptome of wild type and selected strains of the microalgae Tisochrysis lutea provides insights into the genetic basis, lipid metabolism and the life cycle. PLOS ONE 2014. 
601

602

603

604

605

606

607

608

609

610

611

612

613

614

615

616

617

618

619

620

621

622

623

624

625

626

627

628

629

630

631

632

633

634

635

636

637

638

639

640

641

642
[36] Marchler-Bauer A, Lu S, Anderson JB, Chitsaz F, Derbyshire MK, DeWeese-Scott C, et al. CDD: a Conserved Domain Database for the functional annotation of proteins. Nucleic Acids Res 2011;39:D225-229.

[37] Corpet F, Gouzy J, Kahn D. The ProDom database of protein domain families. Nucleic Acids Res 1998;26:323-6.

[38] Käll L, Krogh A, Sonnhammer ELL. A combined transmembrane topology and signal peptide prediction method. J Mol Biol 2004;338:1027-36.

[39] Hirokawa T, Boon-Chieng S, Mitaku S. SOSUI: classification and secondary structure prediction system for membrane proteins. Bioinformatics 1998;14:378-9.

[40] Markou G, Angelidaki I, Georgakakis D. Microalgal carbohydrates: an overview of the factors influencing carbohydrates production, and of main bioconversion technologies for production of biofuels. Appl Microbiol Biotechnol 2012;96:631-45.

[41] Shifrin N, Chisholm S. Phytoplankton Lipids - Interspecific Differences and Effects of Nitrate, Silicate and Light-Dark Cycles. J Phycol 1981;17:374-84.

[42] Reitan KI, Rainuzzo JR, Olsen Y. Effect of Nutrient Limitation on Fatty Acid and Lipid Content of Marine Microalgae1. J Phycol 1994;30:972-9.

[43] Griffiths M, van Hille R, Harrison S. Lipid productivity, settling potential and fatty acid profile of 11 microalgal species grown under nitrogen replete and limited conditions. J Appl Phycol 2012;24:989-1001.

[44] Liu CP, Lin LP. Ultrastructural study and lipid formation of Isochrysis sp CCMP1324. Bot Bull Acad Sin 2001;42:207-14.

[45] Wang ZT, Ullrich N, Joo S, Waffenschmidt S, Goodenough U. Algal Lipid Bodies: Stress Induction, Purification, and Biochemical Characterization in Wild-type and Starch-less Chlamydomonas reinhardtii. Eukaryot Cell 2009:EC.00272-09.

[46] Cooper MS, Hardin WR Pete e TW C tt i c R. Vi u izi "g ee i " i ive algal cells. J Biosci Bioeng 2010;109:198-201.

[47] Work V, Radakovits R, Jinkerson R, Meuser J, Elliott L, Vinyard D, et al. Increased Lipid Accumulation in the Chlamydomonas reinhardtii sta7-10 Starchless Isoamylase Mutant and Increased Carbohydrate Synthesis in Complemented Strains. Eukaryot CELL 2010;9:1251-61.

[48] Miller R, Wu G, Deshpande R, Vieler A, Gartner K, Li X, et al. Changes in Transcript Abundance in Chlamydomonas reinhardtii following Nitrogen Deprivation Predict Diversion of Metabolism. PLANT Physiol 2010;154:1737-52.

[49] Droop M. Vitamin-B12 and Marine Ecology .4. the Kinetics of Uptake, Growth and Inhibition in Monochrysis-Lutheri. Curr ContentsAgriculture Biol Environ Sci 1985:1616.

[50] Livne A, Sukenik A. Lipid Synthesis and Abundance of Acetyl CoA Carboxylase in Isochrysis galbana (Prymnesiophyceae) Following Nitrogen Starvation. Plant Cell Physiol 1992;33:1175-81.

[51] Fujiwara S, Tsuzuki M, Kawachi M, Minaka N, Inouye I. Molecular phylogeny of the Haptophyta based on the $\mathrm{rbcL}$ gene and sequence variation in the spacer region of the RUBISCO operon. J Phycol 2001;37:121-9.

[52] Longworth J, Noirel J, Pandhal J, Wright PC, Vaidyanathan S. HILIC- and SCX-based quantitative proteomics of Chlamydomonas reinhardtii during nitrogen starvation induced lipid and carbohydrate accumulation. J Proteome Res 2012.

[53] Msanne J, Xu D, Konda AR, Casas-Mollano JA, Awada T, Cahoon EB, et al. Metabolic and gene expression changes triggered by nitrogen deprivation in the photoautotrophically grown microalgae Chlamydomonas reinhardtii and Coccomyxa sp. C-169. Phytochemistry 2012;75:50-9. 
643

644

645

646

647

648

649

650

651

652

653

654

655

656

657

658
[54] James GO, Hocart CH, Hillier W, Chen H, Kordbacheh F, Price GD, et al. Fatty acid profiling of Chlamydomonas reinhardtii under nitrogen deprivation. Bioresour Technol 2011;102:3343-51.

[55] Allen AE, LaRoche J, Maheswari U, Lommer M, Schauer N, Lopez PJ, et al. Wholecell response of the pennate diatom Phaeodactylum tricornutum to iron starvation. Proc Natl Acad Sci 2008;105:10438-43.

[56] Vallon O, Bulté L, Kuras R, Olive J, Wollman F-A. Extensive accumulation of an extracellular 1-amino-acid oxidase during gametogenesis of Chlamydomonas reinhardtii. Eur J Biochem 1993;215:351-60.

[57] Cantarel BL, Coutinho PM, Rancurel C, Bernard T, Lombard V, Henrissat B. The Carbohydrate-Active EnZymes database (CAZy): an expert resource for Glycogenomics. Nucleic Acids Res 2009;37:D233-238.

[58] St John FJ, González JM, Pozharski E. Consolidation of glycosyl hydrolase family 30: A dual domain 4/7 hydrolase family consisting of two structurally distinct groups. FEBS Lett 2010;584:4435-41. 
Falb 1-NSS identificátion of spots.

\begin{tabular}{|c|c|c|c|c|c|c|}
\hline Class & $\mathbf{N}^{\circ}$ spot & $\begin{array}{l}\mathrm{Mr}(\mathbf{k D a}) / \mathrm{PI} \\
\text { experimental }\end{array}$ & $\begin{array}{c}\mathrm{Mr}(\mathbf{k D a}) / \mathrm{PI} \\
\text { theoretical }\end{array}$ & $\begin{array}{l}\text { Unique peptide } \\
\text { matched }\end{array}$ & Hypothetical function & $\begin{array}{c}\text { NCBI accession } \\
\text { number }\end{array}$ \\
\hline \multirow{2}{*}{$\begin{array}{l}\text { Lipid } \\
\text { metabolism }\end{array}$} & 1224 & $90 / 6.5$ & $78 / 5.9$ & 50 & \multirow{2}{*}{$\begin{array}{l}\text { acetyl-CoA/propionyl-CoA carboxylase } \\
\text { FabG }\end{array}$} & KF233705 \\
\hline & 3009 & $35 / 6.2$ & $30 / 8.5$ & 18 & & KF233706 \\
\hline \multirow{6}{*}{$\begin{array}{l}\text { Carbohydrate } \\
\text { catabolism }\end{array}$} & 1074 & $110 / 5.2$ & \multirow{2}{*}{$99 / 4.5$} & 35 & \multirow{2}{*}{ Glycoside hydrolase family GH30 } & \multirow{2}{*}{ KF233707 } \\
\hline & 1078 & $110 / / 5.3$ & & 30 & & \\
\hline & 1215 & $90 / 5.8$ & \multirow{4}{*}{$81 / 6.1$} & 58 & \multirow{4}{*}{ Glycoside hydrolase family GH16 } & \multirow{4}{*}{ KF233708 } \\
\hline & 1221 & $90 / 6.0$ & & 163 & & \\
\hline & 1238 & $90 / 6.1$ & & 106 & & \\
\hline & 1241 & $90 / 6.2$ & & 37 & & \\
\hline \multirow{4}{*}{$\begin{array}{l}\text { Amino acid } \\
\text { metabolism }\end{array}$} & 1108 & $105 / 4.6$ & \multirow{3}{*}{$108 / 4.4$} & 30 & \multirow{3}{*}{ Periplasmic L-amino acid oxidase } & \multirow{3}{*}{ KF233709 } \\
\hline & 1144 & $105 / 4.7$ & & 74 & & \\
\hline & 1173 & $100 / 4.7$ & & 88 & & \\
\hline & 3981 & $90 / 5.85$ & $78 / 5.7$ & 141 & Glutamine synthetase III & KF233710 \\
\hline \multirow{12}{*}{$\begin{array}{l}\text { Energy } \\
\text { metabolism; } \\
\text { photosynthesis. }\end{array}$} & 1787 & $65 / 4.6$ & $54 / 5.9$ & 19 & RBCL & KF233711 \\
\hline & 3774 & $10 / 6.6$ & \multirow{2}{*}{$9.2 / 4.7$} & 15 & \multirow{2}{*}{ RBCS } & \multirow{2}{*}{ KF233712 } \\
\hline & 3798 & $10 / 5.7$ & & 26 & & \\
\hline & 3971 & $65 / 4.8$ & $51 / 4.6$ & 72 & ATP synthase CF1 beta subunit & KF233713 \\
\hline & 1926 & $60 / 4.9$ & $54 / 5$ & 23 & & \\
\hline & 1884 & $60 / 4.95$ & $54 / 5$ & 44 & Ubiquinol: Cytochrome c oxidoreductase $50 \mathrm{kDa}$ core 1 subunit & KF233714 \\
\hline & 1544 & $60 / 5.6$ & $66 / 5.1$ & 150 & ATP synthase & KF233715 \\
\hline & 2310 & $42 / 6.4$ & $50 / 5.6$ & 38 & Chloroplast ferredoxin $\mathrm{NADP}(+)$ reductase & KF233716 \\
\hline & 1354 & $75 / 5.1$ & $77 / 6.6$ & 31 & Ferredoxin & KF233717 \\
\hline & 2250 & $40 / 6.7$ & $36 / 5.9$ & 12 & GAPDH & KF233718 \\
\hline & 1696 & $65 / 5.7$ & & 61 & & \\
\hline & 3937 & $73 / 5.5$ & $37 / 4.9$ & 14 & GAPDH & KF233719 \\
\hline & 2474 & $40 / 5.2$ & $37.4 / 4.4$ & 20 & 30S Plastidal ribosomal protein S1 & KF233720 \\
\hline Translation & 3193 & $22 / 5.8$ & $20 / 9.8$ & 14 & 30S Plastidal ribosomal protein S15 & KF233721 \\
\hline & 3954 & $47 / 4.9$ & $34 / 5.0$ & 34 & 30S Plastidal ribosomal protein S1 & KF233722 \\
\hline Pigment & 2214 & $42 / 5.2$ & $37 / 4.4$ & 44 & Uroporphyrinogen decarboxylase, chloroplast precursor & KF233723 \\
\hline biosynthesis & 2215 & $42 / 5.3$ & $41 / 5.2$ & 23 & Chloroplast coproporphyrinogen III oxidase & KF233724 \\
\hline process & 2425 & $40 / 4.7$ & $34 / 4.5$ & 6 & Geranylgeranyl pyrophosphate synthetase & KF233725 \\
\hline & 3757 & $13 / 6.3$ & $14 / 6$ & 9 & Superoxide dismutase Ni-type (SOD) & KF233726 \\
\hline & 1585 & $75 / 6$ & $51 / 4.6$ & 8 & Protein disulfide isomerase (Pdi) & KF233727 \\
\hline & 1066 & $115 / 5.8$ & $90 / 5.4$ & 131 & Clp protease ATP binding subunit & KF233728 \\
\hline Stress & 1342 & $90 / 5.3$ & $135 / 4.5$ & 47 & HSP60 & KF233729 \\
\hline & 1184 & $100 / 4.7$ & & 53 & & \\
\hline & 1191 & $100 / 4.8$ & $72 / 7.9$ & 71 & Luminal binding HSP70 & KF233730 \\
\hline Cell division & 2801 & $32 / 5.8$ & $30 / 5.1$ & 37 & Septum-site determining protein & KF233731 \\
\hline & 2313 & $42 / 5.9$ & $34 / 5.0$ & 10 & MORN repeat domain containing conserved unknown protein & KF233732 \\
\hline & 3951 & $75 / 5$ & $70 / 4.7$ & 106 & Coccolith scale associated protein-1 & KF233733 \\
\hline Conserved & 2681 & $37 / 6.1$ & $31 / 5.7$ & 22 & FabG domain containing conserved unknown protein & KF233734 \\
\hline $\begin{array}{l}\text { unknown } \\
\text { proteins }\end{array}$ & 1500 & $75 / 5.0$ & $58 / 4.8$ & 41 & NAD-Rossmann-fold domain containing conserved unknown protein 1 & KF233735 \\
\hline & 2291 & $40 / 5.5$ & $43 / 5.4$ & 15 & NAD-Rossmann-fold domain containing conserved unknown protein 2 & KF233736 \\
\hline & 2978 & $27 / 6.0$ & $27 / 6.2$ & 106 & Conserved unknown protein 28404 & KF233737 \\
\hline & 2824 & $30 / 6.2$ & $25 / 5.1$ & 20 & Unknown protein 18353 & KF233738 \\
\hline & 3934 & $30 / 5.0$ & $27 / 4.4$ & 33 & Unknown protein 27667 & KF233739 \\
\hline & 2763 & $30 / 5.1$ & $27 / 4.5$ & 24 & Unknown protein 36678 & KF233740 \\
\hline & 1378 & $90 / 5.5$ & & 35 & & \\
\hline & 1455 & $80 / 5.6$ & $58 / 5.1$ & 21 & C1 Peptidase domain-containing unknown protein 34982 & KF233741 \\
\hline & 3973 & & & 21 & & \\
\hline Unknown & 1915 & $55 / 4.8$ & $37 / 4.8$ & 25 & Unknown protein 1821 & KF233742 \\
\hline proteins & 2115 & $48 / 5.2$ & & 16 & & \\
\hline & 1896 & $65 / 4.6$ & $45 / 4.7$ & 9 & Methyltransferase domain containing unknown protein 30039 & KF233743 \\
\hline & 2940 & $26 / 4.6$ & & 10 & & \\
\hline & 2966 & $24 / 4.6$ & & 4 & & \\
\hline & 3008 & $25 / 4.6$ & $25 / 4.7$ & 10 & Unknown protein 27017 & KF233744 \\
\hline & 3940 & $29 / 4.2$ & & 14 & & \\
\hline & 3963 & $30 / 4.3$ & & 12 & & \\
\hline
\end{tabular}


Tab 2 - Protein down accumulated in WT and S2M2 strains during nitrogen starvation.

\begin{tabular}{|c|c|c|c|c|c|c|}
\hline \multirow{2}{*}{ Hypothetical function } & \multicolumn{2}{|r|}{ WT } & \multicolumn{2}{|r|}{ S2M2 } & \multirow{2}{*}{$\mathbf{N}^{\circ}$ spot } & \multirow{2}{*}{ Class } \\
\hline & Fold & ANOVA (p) & Fold & ANOVA (p) & & \\
\hline FabG & 2.5 & $8.069 \mathrm{e}^{-8}$ & 1.2 & 0.02 & 3009 & Lipid metabolism \\
\hline $\begin{array}{l}\text { FabG domain-containing conserved } \\
\text { unknown protein }\end{array}$ & 4.7 & $2.524 \mathrm{e}^{-8}$ & 1.5 & 0.025 & 2681 & Conserved unknown proteins \\
\hline RBCL & 3.0 & 0.002 & 2.0 & 0.0054 & 1787 & \multirow{4}{*}{$\begin{array}{l}\text { Energy metabolism; } \\
\text { photosynthesis }\end{array}$} \\
\hline \multirow{2}{*}{ RBCS } & 3.3 & $2.426 \mathrm{e}^{-5}$ & 2.6 & $0.339 \mathrm{e}^{-3}$ & 3774 & \\
\hline & 2.8 & $1.793 \mathrm{e}^{-5}$ & 2.2 & $6.14 \mathrm{e}^{-5}$ & 3798 & \\
\hline ATP synthase CF1 beta subunit & 2.4 & $5.457 \mathrm{e}^{-4}$ & 2.0 & 0.049 & 3971 & \\
\hline 30S Plastidal ribosomal protein S1 & 2.0 & $5.479 \mathrm{e}^{-7}$ & 1.8 & $0.168 \mathrm{e}^{-3}$ & 2474 & \multirow{3}{*}{ Translation } \\
\hline 30S Plastidal ribosomal protein S15 & 2.5 & $7.272 \mathrm{e}^{-5}$ & 2.1 & $0.287 \mathrm{e}^{-3}$ & 3193 & \\
\hline 30S Plastidal ribosomal protein S1 & 2.6 & $4.852 \mathrm{e}^{-6}$ & 1.8 & $0.929 \mathrm{e}^{-3}$ & 3954 & \\
\hline $\begin{array}{l}\text { Uroporphyrinogen decarboxylase, } \\
\text { chloroplast precursor [Ectocarpus } \\
\text { siliculosus] }\end{array}$ & 3.1 & $2.913 \mathrm{e}^{-9}$ & 2.1 & $4.22 \mathrm{e}^{-5}$ & 2214 & \multirow{3}{*}{ Pigment biosynthetic process } \\
\hline Chloroplast coproporphyrinogen III oxidase & 2.1 & $8.939 \mathrm{e}^{-7}$ & 1.6 & $1.44 \mathrm{e}^{-3}$ & 2215 & \\
\hline Geranylgeranyl pyrophosphate synthetase & 2.4 & $2.478 \mathrm{e}^{-5}$ & 1.5 & $2.88 \mathrm{e}^{-3}$ & 2425 & \\
\hline Unknown protein 18353 & 4.4 & $3.530 \mathrm{e}^{-9}$ & 2.5 & $5.54 \mathrm{e}^{-5}$ & 2824 & \multirow{3}{*}{ Unknown proteins } \\
\hline Unknown protein 27667 & 3.0 & $5.557 \mathrm{e}^{-7}$ & 1.9 & $3.19 \mathrm{e}^{-5}$ & 3934 & \\
\hline Unknown protein 36678 & 4.4 & $1.246 \mathrm{e}^{-7}$ & 1.5 & $4.85 \mathrm{e}^{-3}$ & 2763 & \\
\hline
\end{tabular}


Table 3

Click here to download Table: Tab 3.doc

Tab 3 - Protein up accumulated in WT and S2M2 strains during nitrogen starvation.

\begin{tabular}{|lcccccl|}
\hline \multirow{2}{*}{ Hypothetical function } & \multicolumn{2}{c}{ WT } & \multicolumn{2}{c|}{ S2M2 } & \multirow{2}{*}{ No spot } & Class \\
& Fold & ANOVA (p) & Fold & ANOVA (p) & & \\
\hline Acetyl-CoA/propionyl-CoA carboxylase & 2.9 & 0.003 & 1.6 & 0.196 & 1224 & Lipid metabolism \\
\hline \multirow{2}{*}{ Periplasmic L-amino acid oxidase } & 8.2 & $7.794 \mathrm{e}^{-7}$ & 1.2 & 0.44 & 1108 & \multirow{2}{*}{ Amino acid metabolism } \\
\hline Coccolith scale associated protein-1 (CSAP- & 4.3 & $1.160 \mathrm{e}^{-6}$ & 1.2 & 0.277 & 1144 & \\
1 1) & 6.2 & $2.802 \mathrm{e}^{-6}$ & 2.4 & $2.22 \mathrm{e}^{-3}$ & \multirow{2}{*}{3951} & \multirow{2}{*}{ Conserved unknown proteins } \\
\hline
\end{tabular}


Tab 4 - Protein down accumulated in S2M2 strain

\begin{tabular}{|c|c|c|c|c|c|c|}
\hline \multirow[b]{2}{*}{ Hypothetical function } & \multicolumn{2}{|c|}{ Exponential phase } & \multicolumn{2}{|c|}{ Stationary phase } & \multirow[b]{2}{*}{$\mathbf{N}^{\circ}$ spot } & \multirow[b]{2}{*}{ Class } \\
\hline & Fold & ANOVA (p) & Fold & ANOVA (p) & & \\
\hline Glutamine synthetase III & 1.8 & 0.066 & 1.8 & 0.005 & 3981 & \multirow{3}{*}{ Amino acid metabolism } \\
\hline \multirow{2}{*}{ Periplasmic L-amino acid oxidase } & 1.3 & 0.294 & off & $7.794 \mathrm{e}^{-5}$ & 1108 & \\
\hline & 1.4 & 0.014 & off & $1.160 \mathrm{e}^{-4}$ & 1144 & \\
\hline ATP synthase & 1.9 & 0.017 & 2.5 & $6.6 \mathrm{e}^{-5}$ & 1544 & \multirow{3}{*}{$\begin{array}{l}\text { Energy metabolism; } \\
\text { photosynthesis. }\end{array}$} \\
\hline Chloroplast ferredoxin NADP(+) reductase & 2.0 & $0.221 \mathrm{e}^{-3}$ & 2.2 & $0.33 \mathrm{e}^{-3}$ & 2310 & \\
\hline Ferredoxin & off & $1.49 \mathrm{e}^{-5}$ & off & $3.339 \mathrm{e}^{-5}$ & 1354 & \\
\hline \multirow{2}{*}{$\begin{array}{l}\text { Clp protease ATP binding subunit } \\
\text { HSP60 }\end{array}$} & 1.7 & 0.013 & 2.3 & $4.11 \mathrm{e}^{-4}$ & 1066 & \multirow{4}{*}{ Stress } \\
\hline & 1.5 & 0.019 & off & $5.08 \mathrm{e}^{-5}$ & 1342 & \\
\hline \multirow{2}{*}{ Luminal binding HSP70 } & off & $0.652 \mathrm{e}^{-3}$ & off & 0.027 & 1184 & \\
\hline & off & 0.026 & off & 0.009 & 1191 & \\
\hline Coccolith scale associated protein-1 & 1.2 & 0.557 & 2.1 & 0.017 & 3951 & \multirow[b]{2}{*}{ Conserved unknown proteins } \\
\hline $\begin{array}{l}\text { NAD-Rossmann-fold domain containing } \\
\text { conserved unknown protein } 1\end{array}$ & off & $1.04 \mathrm{e}^{-7}$ & off & $9.504 \mathrm{e}^{-5}$ & 1500 & \\
\hline Unknown protein & 2.1 & $7.95 \mathrm{e}^{-4}$ & 1.4 & 0.073 & 2763 & \multirow{7}{*}{ Unknown proteins } \\
\hline Unknown protein & 1.2 & 0.358 & 2.9 & 0.019 & 3973 & \\
\hline \multirow{5}{*}{$\begin{array}{l}\text { Methyltransferase domain containing } \\
\text { unknown protein } \\
\text { C1_Peptidase domain containing unknown } \\
\text { protein } \\
\text { Unknown protein } 1821 \\
\text { Unknown protein } 27017\end{array}$} & 1.6 & $0.7 \mathrm{e}^{-2}$ & 2.1 & 0.0054 & 1896 & \\
\hline & 4.1 & $1.08 \mathrm{e}^{-5}$ & off & $1.06 \mathrm{e}^{-5}$ & 1378 & \\
\hline & off & $2.73 \mathrm{e}^{-5}$ & off & $3.5 \mathrm{e}^{-4}$ & 1915 & \\
\hline & off & $7.83 \mathrm{e}^{-5}$ & off & $1.23 \mathrm{e}^{-5}$ & 3940 & \\
\hline & off & $8.57 \mathrm{e}^{-4}$ & off & $6.91 \mathrm{e}^{-5}$ & 3963 & \\
\hline
\end{tabular}




\begin{tabular}{|c|c|c|c|c|c|c|}
\hline \multirow[b]{2}{*}{ Hypothetical function } & \multicolumn{2}{|c|}{ Exponential phase } & \multicolumn{2}{|c|}{ Stationary phase } & \multirow{2}{*}{$\begin{array}{l}\mathbf{N}^{\circ} \\
\text { spot }\end{array}$} & \multirow[b]{2}{*}{ Class } \\
\hline & Fold & ANOVA (p) & Fold & $\begin{array}{l}\text { ANOVA } \\
(\mathbf{p})\end{array}$ & & \\
\hline FabG & 1.1 & 0.55 & 2.5 & $7.37 \mathrm{e}^{-5}$ & 3009 & Lipid metabolism \\
\hline \multirow{2}{*}{ Glycosyl hydrolase family GH30 } & on & $9.25 \mathrm{e}^{-6}$ & on & $1.331 \mathrm{e}^{-6}$ & 1074 & \multirow{6}{*}{ Glucide catabolism } \\
\hline & on & $9.12 \mathrm{e}^{-6}$ & on & $2.60 \mathrm{e}^{-4}$ & 1078 & \\
\hline \multirow{4}{*}{ Glycosyl hydrolase family GH16 } & on & $1.93 \mathrm{e}^{-5}$ & on & $2.1 \mathrm{e}^{-5}$ & 1221 & \\
\hline & on & $1.73 \mathrm{e}^{-7}$ & on & $4.07 \mathrm{e}^{-7}$ & 1238 & \\
\hline & on & $5.36 \mathrm{e}^{-5}$ & on & $8.0 \mathrm{e}^{-5}$ & 1241 & \\
\hline & 2.1 & 0.002 & 1.3 & 0.135 & 1215 & \\
\hline Septum-site determining protein & 1.4 & 0.16 & 2.3 & $8.42 \mathrm{e}^{-7}$ & 2801 & Cell division \\
\hline \multirow{2}{*}{$\begin{array}{l}\text { Ubiquinol:cytochrome c oxidoreductase } \\
50 \mathrm{kDa} \text { core } 1 \text { subunit }\end{array}$} & on & $8.15 \mathrm{e}^{-6}$ & 1.3 & 0.118 & 1884 & \multirow{5}{*}{$\begin{array}{l}\text { Energy metabolism; } \\
\text { photosynthesis. }\end{array}$} \\
\hline & on & $9.5 \mathrm{e}^{-8}$ & on & $8.59 \mathrm{e}^{-5}$ & 1926 & \\
\hline GAPDH & 1.3 & 0.211 & 2.5 & $3.46 \mathrm{e}^{-4}$ & 2250 & \\
\hline GAPDH & 2.0 & $2.72 \mathrm{e}^{-5}$ & 2.2 & $1.97 \mathrm{e}^{-4}$ & 1696 & \\
\hline GAPDH & 2.0 & $1.52 \mathrm{e}^{-4}$ & 3.2 & $2.38 \mathrm{e}^{-7}$ & 3937 & \\
\hline Superoxide dismutase Ni-type (SOD) & 1.2 & 0.565 & 2.0 & $2.0 \mathrm{e}^{-4}$ & 3757 & \multirow{2}{*}{ Stress } \\
\hline Protein disulfide isomerase (Pdi) & 2.6 & $7.67 \mathrm{e}^{-5}$ & 1.6 & 0.0016 & 1585 & \\
\hline $\begin{array}{l}\text { NAD-Rossmann-fold domain containing } \\
\text { conserved unknown protein } 2\end{array}$ & on & $9.23 \mathrm{e}^{-6}$ & on & 0.0017 & 2291 & \multirow{4}{*}{$\begin{array}{l}\text { Conserved unknown } \\
\text { proteins }\end{array}$} \\
\hline $\begin{array}{l}\text { FabG domain-containing conserved } \\
\text { unknown protein }\end{array}$ & 1.2 & 0.206 & 4.7 & $2.524 \mathrm{e}^{-5}$ & 2681 & \\
\hline $\begin{array}{l}\text { MORN repeat domain containing } \\
\text { conserved unknown protein }\end{array}$ & 1.5 & 0.039 & 2.1 & $3.43 \mathrm{e}^{-5}$ & 2313 & \\
\hline Conserved unknown protein & 1.3 & 0.027 & 2.0 & $4.27 \mathrm{e}^{-5}$ & 2978 & \\
\hline Unknown protein 1821 & on & $8.97 \mathrm{e}^{-5}$ & on & 0.179 & 2115 & \multirow{5}{*}{ Unknown proteins } \\
\hline Unknown protein 27017 & on & 0.004 & on & $1.19 \mathrm{e}^{-4}$ & 2940 & \\
\hline Unknown protein 27017 & on & $9.632 \mathrm{e}^{-5}$ & on & 0.016 & 3008 & \\
\hline $\begin{array}{l}\text { C1 Peptidase domain-containing } \\
\text { unknown protein }\end{array}$ & 3.1 & $3.91 \mathrm{e}^{-4}$ & 2.5 & $4.96 \mathrm{e}^{-6}$ & 1455 & \\
\hline Unknown protein 27017 & 2.7 & $6.77 \mathrm{e}^{-5}$ & 3.4 & $3.35 \mathrm{e}^{-5}$ & 2966 & \\
\hline
\end{tabular}


$\begin{array}{llll}\text { Hypotetical function } & \mathrm{N}^{\circ} \text { spot } & \text { WTstrain } & \text { S2M2 strain }\end{array}$

PLAAOx

$1108-$

1144

FabG

3009
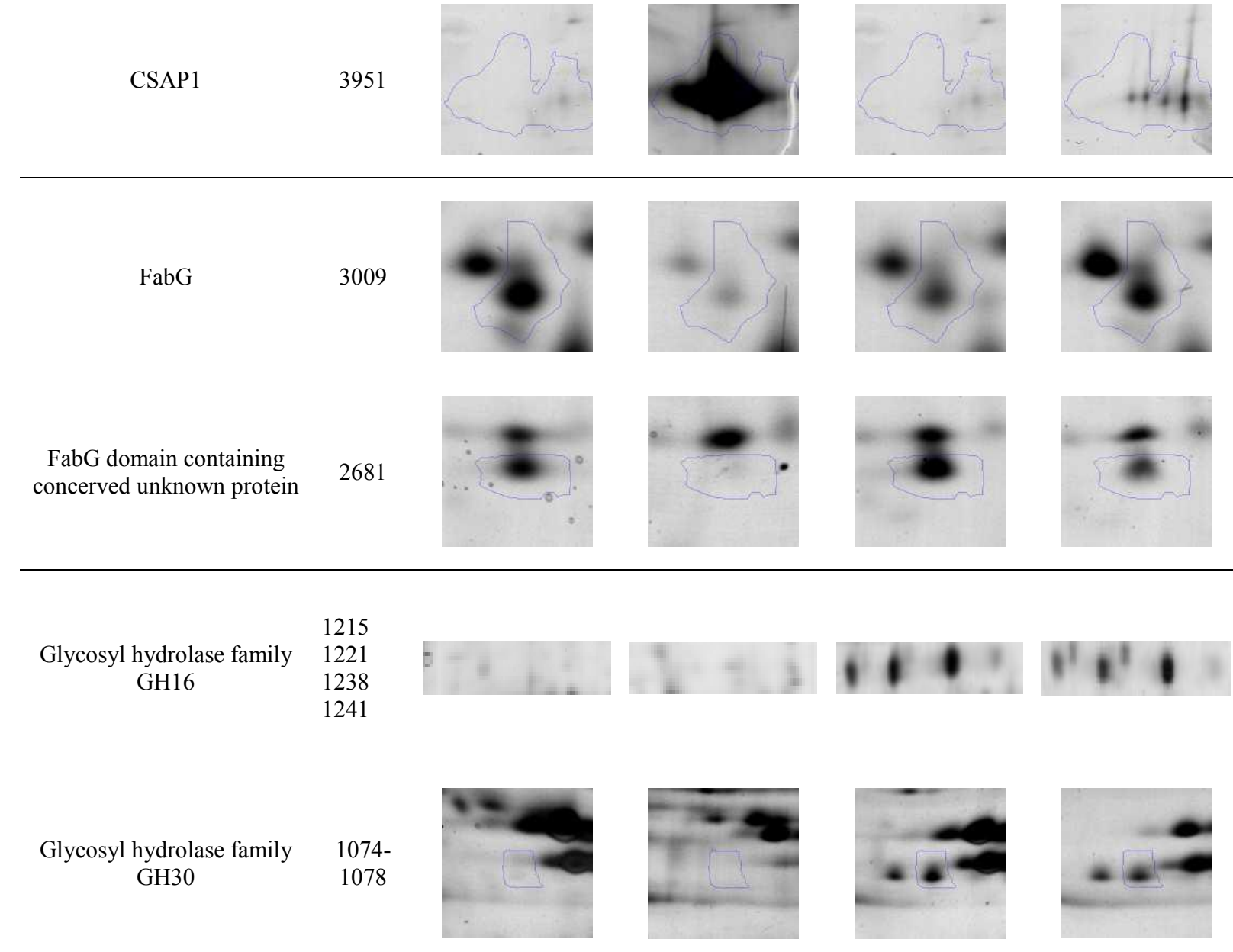

FabG domain containing concerved unknown protein

121

GH16

GH30
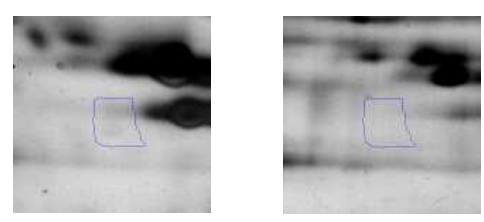
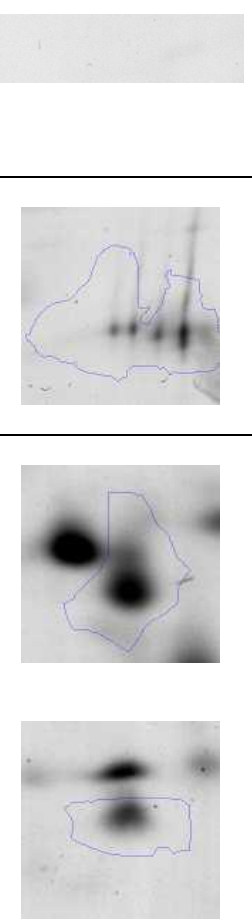
Fig. 3 : Microscopic observations of Tisochrysis lutea WT (colum

Click here to download high resolution image
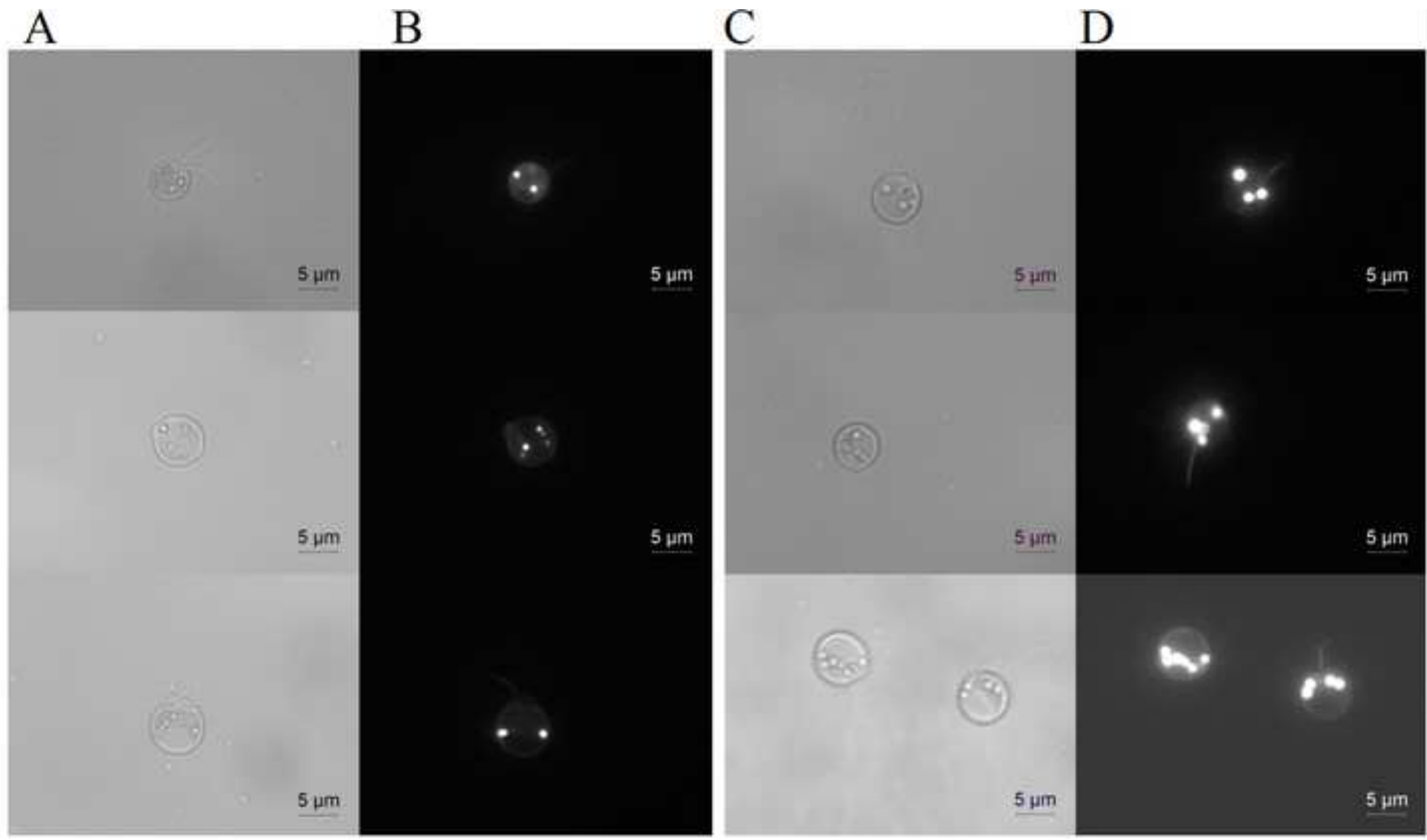

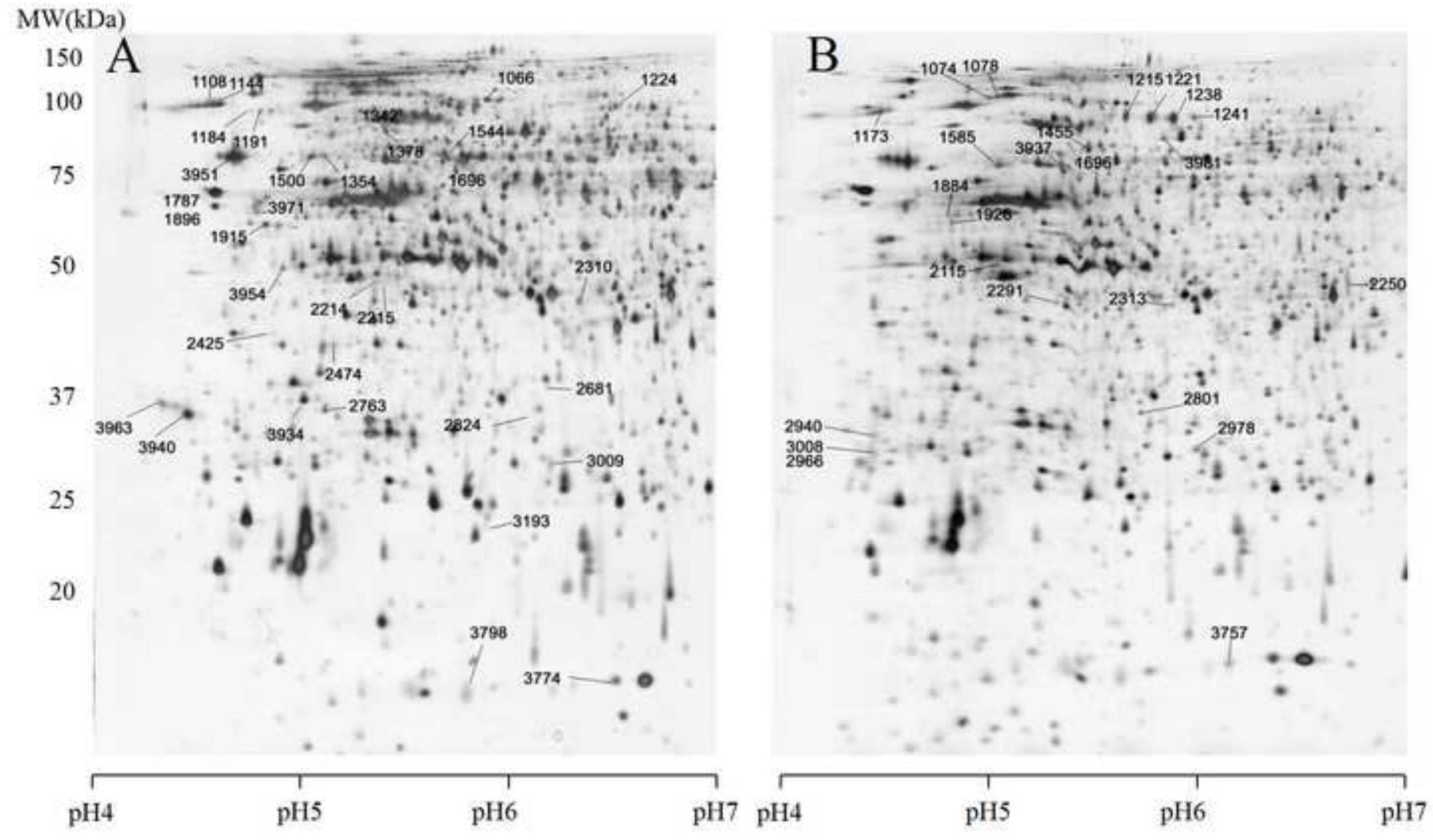
Click here to download high resolution image

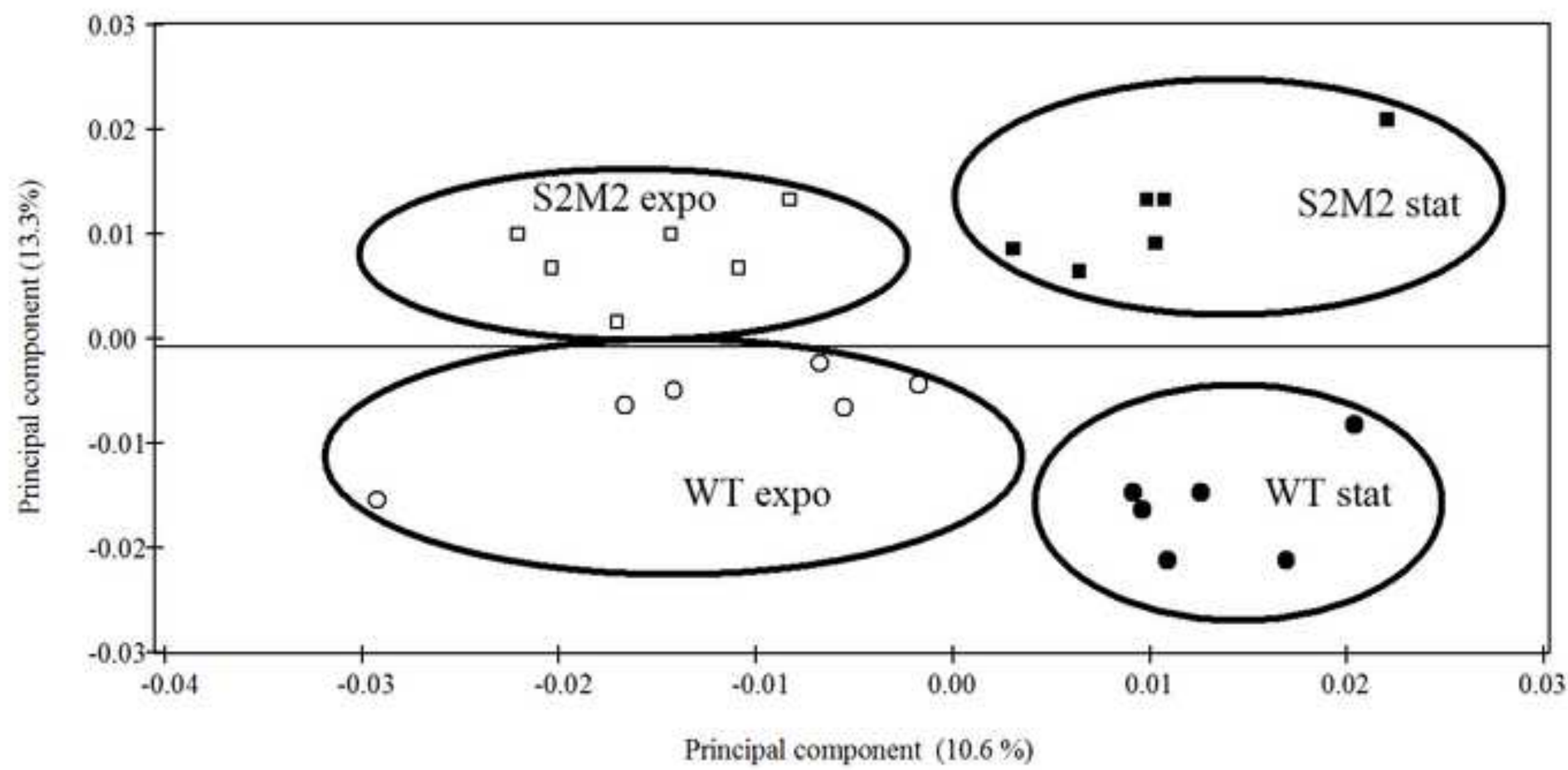


Supplementary material
Click here to download Supplementary material: Supplementary material.doc

click here to down

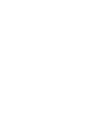

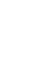

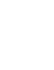
(1)

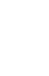
(1) (1) (1) (1) (1) (1) . . . . . . . . . . . . . . . . 